\title{
Population pharmacokinetic analysis of infliximab in patients with ulcerative colitis
}

\author{
Adedigbo A. Fasanmade - Omoniyi J. Adedokun • \\ Joyce Ford • Danika Hernandez • Jewel Johanns • \\ Chuanpu Hu • Hugh M. Davis • Honghui Zhou
}

Received: 12 May 2009 / Accepted: 4 August 2009/Published online: 16 September 2009

(C) The Author(s) 2009. This article is published with open access at Springerlink.com

\begin{abstract}
Purpose Infliximab, a monoclonal antibody, is approved for the treatment of inflammatory diseases at doses that depend on the patient disease population. It was the aim of this study to evaluate its population pharmacokinetics in patients with moderately to severely active ulcerative colitis and characterize patient covariates that affect its disposition in this population.

Methods Information collected from 482 patients in two randomized, double-blind, placebo-controlled international studies were analyzed using NONMEM.

Results A two-compartment, population pharmacokinetic model described the serum infliximab concentration-time data. Population pharmacokinetic estimates (typical value \pm standard error), based on the final covariate model, were clearance (CL: $0.407 \pm 0.0103 \mathrm{~L} /$ day), apparent volumes of distribution in the central $\left(\mathrm{V}_{1}: 3.29 \pm 0.0679 \mathrm{~L}\right)$ and peripheral $\left(\mathrm{V}_{2}: 4.13 \pm 0.16 \mathrm{~L}\right)$ compartments, and intercompartment clearance (Q: $7.14 \pm 0.489 \mathrm{~L} /$ day). Infliximab exhibited interindividual variability for $\mathrm{CL}$ and $\mathrm{V}_{1}$ of $37.7 \%$ and $22.1 \%$, respectively. Infliximab $t_{1 / 2}$ was approximately 14 days. Covariate analysis showed that $\mathrm{V}_{1}$ increased as body weight increased, and CL was higher in patients who developed antibodies to infliximab. An
\end{abstract}

A. A. Fasanmade • O. J. Adedokun · J. Ford • D. Hernandez •

J. Johanns $\cdot \mathrm{C}$. $\mathrm{Hu} \cdot \mathrm{H}$. M. Davis $\cdot$ H. Zhou

Centocor Research and Development, Inc,

Malvern, PA, USA

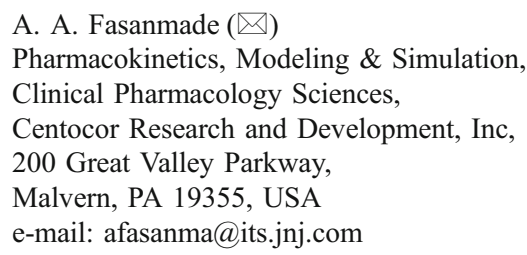

additional novel covariate, serum albumin concentration, was found to be inversely and strongly related to infliximab clearance in this population.

Conclusions The disposition of infliximab in patients with moderately to severely active ulcerative colitis, unlike in rheumatoid arthritis, was not affected by coadministration of immunomodulators and corticosteroids but was related to formation of antibodies to infliximab and, notably, to serum albumin levels.

Keywords Infliximab Population pharmacokinetics . Ulcerative colitis · Immunomodulators Albumin

\section{Introduction}

Infliximab (REMICADE ${ }^{\circledR}$; Centocor Ortho Biotech, Inc.; Malvern, PA, USA) is a recombinant chimeric immunoglobulin (Ig) G1K monoclonal antibody that neutralizes the biologic activity of soluble and membrane-bound tumor necrosis factor alpha (TNF- $\alpha$ ). Infliximab is approved for treatment of rheumatoid arthritis (RA), ankylosing spondylitis (AS), psoriatic arthritis (PSA), psoriasis (PSO), Crohn's disease (CD), and ulcerative colitis (UC) [1].

Across all indications, a linear relationship was observed between the dose administered and maximum serum concentration for adults who received single intravenous infusions of 3-20 mg/kg. The half-life of infliximab in several patient populations has been reported as follows: RA 8-12 days [2]; CD 7.7-9.5 days for single dose [1]; PSO 6.2 -10 days [3]; inflammatory bowel disease (IBD) with multiple doses 18.5 days for terminal half-life [4]; and in a recent review, Klotz et al. summarized that infliximab half-life ranged from 7 to 12 days [5]. The volume of distribution of infliximab was reported to be 3-6 L [5]. 
Serum infliximab concentrations influence the response observed in luminal [6] and fistulizing [7] CD, RA [8], and PSO [3], but there is a high interindividual variability in serum infliximab concentrations during treatment with infliximab. In a previous analysis, we reported the pharmacokinetics (PK) of infliximab in patients with AS where certain patients characteristics affecting infliximab clearance were identified [9]. Similarly, Ternant and colleagues reported an analysis of infliximab PK in patients with IBD [4]; however, this analysis included only two patients with UC. Evidence suggests that therapeutics with infliximab may vary by disease state. For example, rigorous clinical development of infliximab has led to the recommendation of different infliximab dosing regimens among the approved indications. In RA, $3 \mathrm{mg} / \mathrm{kg}$ every 8 weeks (q8w) is the recommended maintenance dose, whereas in AS, $5 \mathrm{mg} / \mathrm{kg}$ q6w is recommended. In $\mathrm{CD}$ and $\mathrm{UC}$, infliximab $5 \mathrm{mg} / \mathrm{kg}$ q8w is recommended as maintenance dose. Despite the common mechanism of action in these inflammatory diseases, the varying dosing requirements for optimal efficacy imply that patients and/or disease characteristics may influence the PK of infliximab differently among patient populations.

Differences in observed efficacy among patient populations with anti-TNF- $\alpha$ therapy is not limited to infliximab. Etanercept is effective in both RA and PSO, but not CD $[10,11]$ at the dose tested. Some reports have attributed the lack of efficacy to lower systemic exposure in the CD patient population compared with RA or PSO populations after etanercept administration despite evidence that TNF- $\alpha$ suppression is effective for these disease states [12]. Irrespective of the reason for lack of effect of etanercept in $\mathrm{CD}$, these observations confirm that patient characteristics may affect anti-TNF- $\alpha$ agents differently.

Patient characteristics can be very different among therapeutic areas; median body weight in RA and PSA in clinical trials of infliximab populations is greater than in the UC population. These and other factors may affect differential drug disposition and efficacy. Thus, it is essential to identify and understand patient characteristics in the different disease populations that can impact the PK of an anti-TNF- $\alpha$ agent. Factors such as development of antibodies to infliximab and administration of concomitant immunomodulators have been suggested to be partially responsible for infliximab serum concentration variability [2]. However, different concomitant medications are generally used in the different disease populations. Therefore, it is important to use a large data pool, when available, to fully identify and accurately quantify important patient characteristics that may impact infliximab $\mathrm{PK}$ in different indications.

In this study, we report the results of population PK analysis of infliximab in patients with UC from two doubleblind, placebo-controlled, phase 3 clinical trials. The results identify a new covariate and quantitatively described all important covariates that were found to influence the PK properties of infliximab in this patient population.

\section{Materials and methods}

\section{Patients}

Active Ulecerative Colitis Trial ACT 1 and ACT 2 were randomized, double-blinded, placebo-controlled, phase 3 clinical trials conducted globally. A total of 728 patients were randomized at 62 sites in ACT $1(N=364)$ and at 55 sites in ACT $2(N=364)$. The institutional review board or ethics committee at each site approved the protocols, and all patients provided informed consent.

\section{Study design}

The design and conduct of these trials have been reported previously [13]. Briefly, all patients had an established diagnosis of UC and moderately to severely active disease with a Mayo score [14] of 6-12 points (range $0-12$; higher scores indicate more severe disease activity) despite concurrent treatment with corticosteroids alone or in combination with azathioprine or 6-mercaptopurine (ACT 1 and 2) or medications containing 5-aminosalicylates (ACT 2 only). Patients diagnosed with indeterminate colitis, Crohn's disease, or clinical findings suggestive of Crohn's disease (i.e., fistula or granulomas on biopsy) were not enrolled. As previously described, concurrent therapy was not required at enrollment for patients who could not tolerate or had had no response to these medications [13]. Doses of concomitant medications remained constant except for corticosteroids, which were tapered by $5 \mathrm{mg}$ weekly after week 8 until a dose of $20 \mathrm{mg} /$ day was reached; thereafter, the dose was reduced by $2.5 \mathrm{mg}$ weekly until discontinuation. Patients were randomized equally $(1: 1: 1)$ to receive intravenous infusions of infliximab at $5 \mathrm{mg} / \mathrm{kg}$ or $10 \mathrm{mg} / \mathrm{kg}$, or placebo at weeks 0,2 , and 6 , and then every 8 weeks through week 22 in ACT 2 or week 46 in ACT 1. Patients were followed for $\mathrm{PK}$ and immune response purposes through week 42 in ACT 2 and week 54 in ACT 1. The duration of each infusion was approximately $2 \mathrm{~h}$.

In ACT 1, blood samples for determining infliximab concentrations were drawn just before and $1 \mathrm{~h}$ after the infusion at weeks $0,2,6,14$, and 46 and just before the infusion at weeks 30 and 38. Additional blood samples for infliximab concentration determination were drawn at weeks 8 and 54 (nondosing visits). In ACT 2, blood samples were drawn just before and $1 \mathrm{~h}$ after the infusion at weeks 0 and 2 and just before the infusion at weeks 6 and 14. Additional blood samples for infliximab concentration 
analysis were drawn at weeks 8,30 , and 42 (nondosing visits). Serum infliximab concentrations were determined using a validated enzyme-linked immunosorbent assay [15] with a lower limit of quantification (LLOQ) of $0.1 \mu \mathrm{g} / \mathrm{ml}$ at a 1:25 dilution. The intra-assay precision, expressed as a coefficient of variation, ranged from $12.87 \%$ to $16.15 \%$, whereas the interassay precision ranged from $12.39 \%$ to $15.94 \%$.

Serum samples analyzed for antibodies to infliximab were collected before infusions at weeks 0 and 30 in both studies and at week 42 in ACT 2 and week 54 in ACT 1. Antibodies to infliximab were determined using an antigenbridging enzyme immunoassay [15]. Patients were classified as positive if antibodies to infliximab were detected at any visit. If antibodies to infliximab were not detected, patients were classified as nonpositive. However, many patients may fall into this category because measurable concentrations of infliximab were present in serum samples at the time antibody to infliximab is being tested. The method is not able to determine whether antibody to infliximab is present (technically, the test would be inconclusive). Some patients had neither detectable infliximab nor antibody to infliximab (negative). For the purpose of our analysis, patients in the last two categories were grouped together. Of the 484 patients randomized to receive infliximab $5 \mathrm{mg} / \mathrm{kg}$ or $10 \mathrm{mg} / \mathrm{kg}$, 482 received at least one infusion and had appropriate serum infliximab concentration data.

\section{Infliximab concentration data}

A total of $96(2.2 \%)$ incongruous or obviously erroneous sample concentrations [most of these were trailing LLOQs (58 of 96)] and were subsequently excluded from the analyses. If, for example, an immediate preinfusion concentration was greater than the immediate postinfusion concentration (usually due to pre-/postinfusion bloodcollection sample-tube switch), both data points were excluded. Also, when there were multiple adjacent infliximab concentrations less than LLOQ in a profile within a single dose interval, the first LLOQ was retained while the other (trailing) LLOQ(s) was excluded from the analysis. One of the 484 patients had an anomalous concentration profile that could not be reasonably accounted for; therefore, this patient's data were excluded from the analysis. After development of an acceptable structural model, potential outliers that had weighted residuals (WRES) $>5.0$ were excluded from the final analysis.

\section{Covariate data}

The baseline covariate value was defined as the last recorded value before the first infliximab dose. For missing covariate baseline values, median values were imputed for continuous covariates, and the category with the highest proportion of patients was imputed for categorical covariates. Sensitivity analysis was performed where appropriate to evaluate the impact of imputed covariate data. Demographic covariates for the population PK data set were age (year), body weight $(\mathrm{kg})$, sex, and race (i.e., Caucasian, African American, Asian, and others). Blood chemistry covariates were biomarkers of kidney function [serum creatinine $(\mathrm{mg} / \mathrm{dl})$, estimated creatinine clearance (CRCL, $\mathrm{ml} / \mathrm{min}$ ) [16], blood urea nitrogen (BUN, $\mathrm{mg} / \mathrm{dl}$ )], liver function [aspartate aminotransferase (AST, U/L), alanine aminotransferase (ALT, U/L), alkaline phosphatase (U/L), bilirubin $(\mathrm{mg} / \mathrm{dl})$ ], clinical chemistry analytes [C-reactive protein $(\mathrm{mg} / \mathrm{dl})$, albumin $(\mathrm{g} / \mathrm{dl})$, total protein $(\mathrm{g} / \mathrm{dl})]$, and hematology parameters [hemoglobin $(\mathrm{g} / \mathrm{dl})$, hematocrit $(\%)$, white blood cell count $\left(\times 10^{9}\right.$ cells $\left./ \mathrm{L}\right)$, platelets $\left(\times 10^{9}\right.$ cells/L), and lymphocytes $\left(\times 10^{9}\right.$ cells $\left.\left./ \mathrm{L}\right)\right]$. Additional covariates were concomitant immunomodulator use (azathioprine, 6mercaptopurine, and/or corticosteroids) and Mayo score at baseline and development of antibodies to infliximab during the trials (i.e., positive anti-infliximab antibody status). Infliximab concentration-time data were analyzed using NONMEM (Version VI, Level 1; ICON Development Solutions, Ellicott City, MD, USA). The programs were run on Microsoft Windows 2000 Professional operating system on an Intel Pentium M processor PC. NONMEM and bootstrap procedures were executed using Wings for NONMEM, version 611 [17]. Xpose4 (Release 6) was used for data visualization and other model diagnostics [18].

Population pharmacokinetic model development

Preliminary data review included the following: checking for potential outlying data points, covariate distribution, scatter plots of concentration versus time, and summary statistics of patient characteristics. Data were analyzed using the first-order conditional estimation method with interaction (FOCE-I) in NONMEM. One, two, and threecompartment models with zero-order infusion and firstorder elimination were explored during the structural model development. Interindividual variability (IIV) with corresponding correlated random effects (i.e., a full variance-covariance matrix) was assumed in all PK parameters. Individual values of PK parameters were assumed to follow a log-normal distribution that was implemented as follows:

$P_{i}=\Theta * \exp \left(\eta_{i}\right)$

where $P_{i}$ is the parameter of interest in the ith patient, $\Theta$ is the estimate of the population mean or the typical value of the parameter, and $\eta_{\mathrm{i}}$ is the deviation from the population mean for the ith patient under the assumption that $\eta_{i}$ is an 
independent random variable with a mean of zero and variance of $\omega^{2}$ ( i.e., $\eta \sim N\left(0, \omega^{2}\right)$. Proportional, additive, or combined-error models were examined to assess the residual variability. For example, a combined additive and proportional-error model was implemented as follows:

$\mathrm{Y}_{\mathrm{ij}}=\mathrm{C}_{\mathrm{ij}}\left(1+\varepsilon_{1 i j}\right)+\varepsilon_{2 i j}$

where $Y_{i j}$ is the $j$ th observed concentration for the ith patient, $\mathrm{C}_{\mathrm{ij}}$ is the corresponding predicted concentration; $\varepsilon_{1 \mathrm{ij}}$ and $\varepsilon_{2 \mathrm{ij}}$ are the residual errors for the proportional and additive components of the model with means of zero and variances of $\sigma_{1}{ }^{2}$ and $\sigma_{2}{ }^{2}$, respectively (i.e., $\varepsilon \sim \mathrm{N}\left(0, \sigma^{2}\right)$. The Akaike information Criteria (AIC) was employed to discriminate nonnested structural models during the structural model exploratory stage and was calculated from the NONMEM objective function value (OFV), as follows:

$\mathrm{AIC}=\mathrm{OFV}+2 * \mathrm{p}$

where $\mathrm{p}$ represents the number of parameters in the model being estimated.

In general, goodness of fit for a given model was assessed by plots of observed infliximab concentrations (DV) versus population-predicted (PRED) and individualpredicted concentrations (IPRED) (i.e., DV vs. PRED and DV vs. IPRED, respectively). The residual error components of models were assessed via scatter plots of weighted residuals (WRES) and conditional weighted residuals (CWRES) versus predicted data (i.e., WRES or CWRES vs. PRED, respectively). Plots of absolute individual weighted residuals (|IWRES|) versus IPRED were also explored. Smooth nonparametric trend curves [locally weighted scatter plot smoother (LOESS)] were included as appropriate to illustrate underlying patterns. Magnitude of random error was also considered in model discrimination. Changes in IIV and residual variability were compared when a new covariate was added to a starting model to explore possible inclusion of such a covariate. In general, a model that converged with a successful covariance step was considered for further analysis, whereas one with any correlation of parameter estimates $>0.95$ was rejected as a preliminary model for subsequent model development.

Covariate model

\section{Covariate screening}

Empirical Bayes estimates (EBEs) were generated from the estimation step in NONMEM. Trends between covariates and PK parameters were graphically examined, as described previously [9]. However, due to potential drawbacks associated with EBE graphical exploration (e.g., subjectiveness and parameter shrinkage) [19], candidate covariates were further tested directly in NONMEM to verify and quantify their relationship with PK parameters. The effects of continuous covariates such as weight on $\mathrm{CL}$, volumes of distribution in the central $\left(\mathrm{V}_{1}\right)$ or peripheral $\left(\mathrm{V}_{2}\right)$ compartments were generally assessed using a function as expressed below:

$\mathrm{P}_{\mathrm{j}}=\mathrm{P}_{\mathrm{pop}} *\left(\frac{\operatorname{Cov}_{j}}{\operatorname{Cov}_{m}}\right)^{\Theta_{c o v}}$

where $P_{j}$ is the model predicted value of a PK parameter $P$ in the jth patient for a given covariate value, $\operatorname{Cov}_{j}$, and $\Theta_{\text {cov }}$ represents a scaling factor for the influence of that covariate. $\mathrm{Cov}_{\mathrm{m}}$ represents the median value of the covariate in the population. $\mathrm{P}_{\text {pop }}$ is thus the typical value of parameter $\mathrm{P}$ corresponding to the median value of the covariate of interest in the population. Categorical covariates such as binary covariates (e.g., gender or use of concomitant medications) were incorporated into the model as index variables and modeled as expressed below:

$\mathrm{P}_{\mathrm{j}}=\mathrm{P}_{\mathrm{pop}} *\left(1+\operatorname{Cov}_{i} * \Theta_{\text {cov }}\right)$

where $\operatorname{Cov}_{i}$ is the numeric index value of the covariate (typically 0 for the reference category or 1 for the comparative category), $P_{j}$ is the model predicted value of the parameter for the $\mathrm{jth}$ patient, $\mathrm{P}_{\text {pop }}$ represents the value of the parameter for the reference covariate value (i.e., when $\operatorname{Cov}_{\mathrm{i}}$ is 0 ) and $\Theta_{\text {cov }}$ represents a multiplicative factor for the influence of that covariate such that if $\Theta_{\text {cov }}$ is less than 0 , the net effect is a decrease in the typical value, and if $\Theta_{\text {cov }}$ is greater than 0 , the net effect is an increase in the typical value of the parameter.

\section{Stepwise covariate modeling}

Stepwise forward addition/backward deletion of covariate modeling approach was adopted during covariate selection. Covariates that individually influenced PK parameters were added in descending order of magnitude with regard to reduction of OFV. The log-likelihood ratio test was the primary criterion used to determine the appropriateness of covariate selection. The full model for covariate effects was built using a stepwise inclusion approach based on a $p$ value of 0.05 , which corresponds to a difference in NONMEM objective function $>3.84$ ( $\chi$-square distribution, 1 degree of freedom). Once a covariate was included in the model, the resulting model became the new model and the remaining covariates were individually retested. This iterative process continued until no additional covariates led to further significant reduction in OFV; therefore, this model was designated the full model.

Following the identification of the full model, model reduction based on backward deletion was implemented 
whereby covariates were eliminated from the full model. The statistical significance of each covariate-parameter relationship was individually assessed during the stepwise deletion phase at the $p<0.001$ level, i.e., only covariates associated with an increase of at least 10.83 in OFV were retained in the model. This stricter criterion was applied due to the multiple comparisons made during the forward addition covariate modeling procedure. In this procedure, a particular covariate parameter in the full model was fixed to its null value, and the model was run to obtain a new OFV. The covariate was then returned to the model and the next covariate parameter was tested in similar manner. This scenario was repeated for each covariate. The covariate with the smallest change in OFV $(\triangle \mathrm{OFV})$ not meeting the prespecified criteria above was then removed from the model. This cycle was repeated in a stepwise fashion until only those covariates producing significant $\triangle \mathrm{OFV}$ remained in the model. The resulting model was regarded as the final model that adequately described the population PK of infliximab in this population of patients with UC.

Population pharmacokinetic model qualification

Bootstrap resampling technique was applied as an internal validation tool to assess the stability of the final parameter estimates and to confirm the robustness of the final model [20]. Two thousand bootstrap replicates were generated by randomly resampling the original data set with replacement. The base and final models were fitted to the replicate data sets. The median values and $95 \%$ confidence intervals (CIs) (i.e., 2.5th and 97.5th percentiles) of these 2,000 bootstrap replicates were compared with the point estimates from the original data set. Model stability was also assessed by calculating the condition number (the ratio of the largest to smallest eigenvalue of the covariance matrix) of the final model, with a value of 1,000 being indicative of illconditioning. The extent of $\eta$ and $\varepsilon$-shrinkage in the PK parameters was also computed according to the following:

$\eta_{\text {shrinkage }}=1-\frac{S D\left(\eta_{E B E, P}\right)}{\omega_{P}}$
$\varepsilon_{\text {shrinkage }}=1-S D($ IWRES $)$

where $\operatorname{SD}\left(\eta_{\mathrm{EBE}, \mathrm{p}}\right)$ is the standard deviation of the empirical Bayes estimates of random effect $(\eta), \omega_{p}$ is the population model estimate of the SD in $\eta$, and SD(IWRES) is the standard deviation of the individual weighted residuals.

\section{External model evaluation}

The external model validation approaches described by Brendel and colleagues were employed [21]. The first approach involved a direct comparison of the population model parameters obtained from the ACT 1 data set with those obtained from the ACT 2 data set. The procedure for the comparison without simulation involved developing base models for ACT 1 and ACT 2 data and comparing the computed PK parameters of ACT 1 to those of ACT 2 using the Wald statistic [21]. Additionally, a posterior predictive check involving Monte Carlo simulations was performed. In this procedure, parameters obtained from ACT 1 population PK model were used to simulate 1,000 data sets based on the ACT 2 study design. The empirical distribution of the parameters obtained from the simulated data sets was then compared with the population PK parameters estimated from the ACT 2 data set itself. Differences between parameters from the simulated and original data sets were compared using two-sided statistical tests at the 0.05 level of significance, as described by Brendel and colleagues [21].

\section{Results}

ACT 1 base model

A two-compartment structural model adequately described the concentration-time profiles of infliximab. The mean population parameter values and the IIVs for the structural model are provided in Table 1. All mean population PK parameter estimates fell within the $95 \%$ CI of bootstrap resampling of 2,000 replicates simulated.

\section{ACT 2 base model}

Similarly, in ACT 2, a two-compartment structural model adequately described the concentration-time profiles of infliximab. Population parameter values for the structural model are provided in Table 1.

Validation of ACT 1 model using ACT 2 data

The most appropriate structural model was determined to be the same for each of the studies after internal validation for each study. With the exception of Q, no significant differences were found between the parameters estimated for the ACT 1 and ACT 2 models (Table 1). The value for $\mathrm{Q}$ is usually difficult to determine accurately; this result may very likely be due to the sparseness of data in ACT 2 . External validation of population PK parameters based on the posterior predictive check involving Monte Carlo simulations of ACT 2 design from ACT 1 did not show any apparent bias. Similarly, histograms of the predictive distribution of simulated population parameters were generally consistent between simulated and actual data (data not 
Table 1 Population pharmacokinetic parameter estimates of infliximab (base models)

\begin{tabular}{|c|c|c|c|c|c|}
\hline \multirow[t]{2}{*}{ Hyperparameter } & \multicolumn{2}{|l|}{ ACT 1} & \multicolumn{2}{|l|}{ ACT 2} & \multirow[t]{2}{*}{$P$ value } \\
\hline & Estimate & RSE (\%) & Estimate & RSE (\%) & \\
\hline CL (L/day) & 0.378 & 2.9 & 0.388 & 3.0 & 0.529 \\
\hline $\mathrm{V}_{1}(\mathrm{~L})$ & 3.17 & 2.0 & 2.99 & 3.3 & 0.129 \\
\hline $\mathrm{V}_{2}(\mathrm{~L})$ & 4.39 & 4.8 & 4.02 & 6.0 & 0.246 \\
\hline Q(L/day) & 6.22 & 8.2 & 10.0 & 8.4 & $<0.001$ \\
\hline$\omega_{\mathrm{CL}}^{2}$ & 0.209 & 10.4 & 0.155 & 11.2 & 0.052 \\
\hline$\omega_{\mathrm{V} 1}^{2}$ & 0.0674 & 14.7 & 0.0938 & 22.8 & 0.254 \\
\hline$\sigma_{\text {add }}$ & 0.0424 & 6.3 & 0.0407 & 3.7 & 0.582 \\
\hline$\sigma_{\text {prop }}$ & 0.399 & 3.5 & 0.411 & 3.1 & 0.524 \\
\hline
\end{tabular}

shown). With the assurance of data set similarity, further analyses used the ACT 1 and ACT 2 combined data set.

Combined data from ACT 1 and ACT 2

In ACT 1 and ACT 2 combined, 483 patients were treated with infliximab and available in the population PK data set; however, data for one patient were excluded because the concentration-time profile was anomalous. A total of 4,145 of 4,310 concentration data points from 482 patients were evaluable and included in the final analysis. Thus, approximately $4 \%$ of data were excluded, primarily attributable to trailing LLOQ values. Overall, an average of approximately 8.6 concentration data points per patient was included in the base model for population PK analysis.

\section{Covariates}

The summary of covariates in the population PK data set is provided in Table 2. At baseline, a majority of patients received aminosalicylates.

\section{Base model for combined ACT 1 and ACT 2 data}

The base model was selected from among structural models tested based on AIC values and goodness-of-fit plots. A two-compartment model with first-order elimination was preferable to a one- or three-compartment model. The two-compartment model had an AIC value of 27046, whereas the one- and three-compartment models had AIC values of 28006 and 27086, respectively. The twocompartment model was parameterized for $\mathrm{CL}, \mathrm{V}_{1}, \mathrm{~V}_{2}$, and Q. Models using a full omega variance-covariance block matrix on all structural parameters or a diagonal variance structure on all or some parameters did not result in acceptable convergence. However, a model with a full omega variance-covariance matrix on $C L$ and $V_{1}$, which assumed similar variance and covariance block for $\mathrm{V}_{2}$ and Q, was successfully implemented. The model with combined proportional and additive residual errors had $\Delta \mathrm{OFV}$ of -215 when compared with the model with only proportional error. Similarly, the model implementing a combined residual error was superior to that with an additive residual error only ( $\triangle \mathrm{OFV}$ of -6002 ). Thus, a combined proportional and additive model was deemed best for describing residual error based on goodness-of-fit plots and lower OFV. The PK parameter estimates \pm standard error (SE) obtained from the base model are shown in Table 3. The terminal half-life for infliximab was about 14 days. Table 3 summarizes the base model parameter estimates and $95 \%$ CIs obtained from the bootstrap.

Goodness-of-fit plots obtained from the base model show that the population and individual predicted values visually match the measured values (Fig. 1). Additionally, residual error plots showed no systematic deviation over time. The mean $( \pm \mathrm{SD})$ of the CWRES was close to zero $[0.04( \pm 0.94)]$, indicating that the model parameters satisfactorily described the data. Histograms of WRES and CWRES appeared approximately normal, with no consistent systematic residual trends.

\section{EBE shrinkage}

The model parameters had fairly moderate levels of $\eta$ shrinkage for CL (10.5\%), $\mathrm{V}_{1}(26.9 \%)$, and $\mathrm{V}_{2}(29.2 \%)$ apart from Q $(58.9 \%)$, suggesting some caution in interpreting covariate relationship based on the EBEs of Q. The magnitude of $\varepsilon$-shrinkage was also low (8.1\%); thus, diagnostic plots of IPRED are expected to reliably detect any structural model anomalies, if present.

Covariate models

\section{Univariate models}

Table 4 shows the impact of some of the covariates on the OFV of population PK model when each covariate was tested on each of the PK parameters. 
Table 2 Summary of demographic and clinical characteristics; patients included in the population pharmacokinetic analysis $(N=482)$
Min minimum, Max maximum, $S D$ standard deviation, $U C$ ulcerative collitis, $A Z A$ azathioprine, 6-MP 6-mercaptopurine, 5-ASA 5-aminosalicylic acid, $A L T$ alanine transaminase, $A S T$ aspartate transaminase

\begin{tabular}{|c|c|c|c|}
\hline Characteristic & Value & Characteristic & Value \\
\hline Demography & & Kidney function & \\
\hline Age, years & & Serum creatinine $(\mathrm{mg} / \mathrm{dl})$ & \\
\hline Mean \pm SD & $41.2 \pm 13.9$ & Number & 477 \\
\hline Median (min, max) & $40(18,81)$ & Mean \pm SD & $0.9 \pm 0.2$ \\
\hline $\begin{array}{l}\text { Gender, } n(\%) \\
\text { Male }\end{array}$ & $293(60.8)$ & $\begin{array}{l}\text { Median (min, max) } \\
\text { Creatinine clearance (ml/min) }\end{array}$ & $0.8(0.3,3.1)$ \\
\hline Female & $189(39.2)$ & Number & 477 \\
\hline Race, $n(\%)$ & & Mean \pm SD & $122.4 \pm 35.4$ \\
\hline $\begin{array}{l}\text { Caucasian } \\
\text { Non-Caucasian }\end{array}$ & $\begin{array}{l}454(94.2) \\
28(5.8)\end{array}$ & $\begin{array}{l}\text { Median (min, max) } \\
\text { Blood urea nitrogen }(\mathrm{mg} / \mathrm{dl})\end{array}$ & $118.4(35.7,325.9)$ \\
\hline Weight, kg & & Number & 477 \\
\hline Mean \pm SD & $78.8 \pm 18.4$ & Mean \pm SD & $13.1 \pm 4.4$ \\
\hline Median (min, max) & $77(40,177.3)$ & Median (min, max) & $12(5,31)$ \\
\hline \multicolumn{2}{|c|}{ Concomitant UC medication, $n(\%)$} & Clinical chemistry & \\
\hline $\begin{array}{l}\text { Baseline AZA/6-MP } \\
\text { Baseline corticosteroid }\end{array}$ & $\begin{array}{l}227(47.1) \\
268(55.6)\end{array}$ & $\begin{array}{l}\text { Albumin }(g / d l) \\
\text { Number }\end{array}$ & 477 \\
\hline Baseline 5-ASA & $350(72.6)$ & Mean \pm SD & $4.1 \pm 0.4$ \\
\hline \multicolumn{2}{|c|}{ Antibodies to infliximab, $n(\%)$} & $\begin{array}{l}\text { Median }(\min , \max ) \\
\text { Total protein }(\mathrm{g} / \mathrm{d} \mathrm{l})\end{array}$ & $4.1(2.4,5.2)$ \\
\hline Nonpositive & $385(79.9)$ & Number & 477 \\
\hline Missing & $64(13.3)$ & Mean \pm SD & $7.2 \pm 0.5$ \\
\hline Disease activity & & Median (min, $\max$ ) & $7.2(5.6,9.5)$ \\
\hline Mayo score & $8.4 \pm 1.6$ & Hematology & \\
\hline $\begin{array}{l}\text { Mean } \pm \mathrm{SD} \\
\text { Median (min, max) }\end{array}$ & $8(4,12)$ & $\begin{array}{l}\text { Hemoglobin }(\mathrm{g} / \mathrm{dl}) \\
\text { Number }\end{array}$ & 472 \\
\hline C-reactive protein $(\mathrm{mg} / \mathrm{dl})$ & & Mean \pm SD & $12.9 \pm 1.7$ \\
\hline $\begin{array}{l}\text { Number } \\
\text { Mean } \pm \text { SD }\end{array}$ & $\begin{array}{l}479 \\
1.4 \pm 2.2\end{array}$ & $\begin{array}{l}\text { Median }(\min , \max ) \\
\text { Hematocrit }(\%)\end{array}$ & $13.1(7.8,17.6)$ \\
\hline Median (min, max) & $0.8(0.2,22.7)$ & $\begin{array}{l}\text { Number } \\
\text { Mean } \pm \text { SD } \\
\text { Median (min, max) }\end{array}$ & $\begin{array}{l}460 \\
38.8 \pm 4.8 \\
38.8(26.1,52.7)\end{array}$ \\
\hline Liver function & & Hematology (cont.) & \\
\hline Alkaline phosphatase (IU/I & & Platelets $\left(\times 10^{9} / \mathrm{L}\right)$ & \\
\hline Number & 477 & Number & 465 \\
\hline Mean \pm SD & $77.3 \pm 33.3$ & Mean \pm SD & $338.6 \pm 105.0$ \\
\hline $\begin{array}{l}\text { Median (min, max) } \\
\text { ALT (IU/L) }\end{array}$ & $72(25,421)$ & $\begin{array}{l}\text { Median (min, max) } \\
\text { White blood cell counts }\left(\times 10^{9} / \mathrm{L}\right)\end{array}$ & $320.5(103,773)$ \\
\hline Number & 477 & Number & 449 \\
\hline Mean \pm SD & $21.7 \pm 16.0$ & Mean \pm SD & $8.4 \pm 3.2$ \\
\hline $\begin{array}{l}\text { Median (min, max) } \\
\text { AST (IU/L) }\end{array}$ & $17(5,180)$ & $\begin{array}{l}\text { Median }(\min , \max ) \\
\text { Lymphocytes }\left(\times 10^{9} / \mathrm{L}\right)\end{array}$ & $7.8(2.3,20.9)$ \\
\hline Number & 477 & Number & 459 \\
\hline Mean \pm SD & $19.6 \pm 9.9$ & Mean \pm SD & $1.5 \pm 0.8$ \\
\hline Median (min, max) & $18(5,98)$ & Median (min, max) & $1.3(0.2,5.7)$ \\
\hline \multicolumn{4}{|l|}{ Total Bilirubin (mg/dL) } \\
\hline Number & 477 & & \\
\hline Mean \pm SD & $0.5 \pm 0.5$ & & \\
\hline Median (min, max) & $0.4(0.1,7.5)$ & & \\
\hline
\end{tabular}


Table 3 Population pharmacokinetic parameter estimates for the ACT 1 and ACT 2 studies (base model and final model)
$C L$ clearance, $V_{l}$ volume of distribution in the central compartment, $V_{2}$ volume of distribution in the peripheral compartment, $Q$ intercompartmental clearance, $I I V$ interindividual variability, $R S E$ relative standard error, $A C T$ Active Ulcerative Colitis Trial. $C I$ confidence interval

${ }^{\text {a }}$ Calculated from 2,000 bootstrap data sets

\begin{tabular}{|c|c|c|c|c|}
\hline \multirow[t]{2}{*}{ Parameter } & \multicolumn{2}{|c|}{ NONMEM } & \multicolumn{2}{|c|}{ Bootstrap $^{a}$} \\
\hline & Estimate & $\%$ RSE & Median & $95 \% \mathrm{CI}$ \\
\hline \multicolumn{5}{|l|}{ Base model } \\
\hline CL (L/day) & 0.384 & 2.3 & 0.383 & $0.366,0.401$ \\
\hline $\mathrm{V}_{1}(\mathrm{~L})$ & 3.09 & 2.9 & 3.1 & $2.83,3.38$ \\
\hline $\mathrm{V}_{2}(\mathrm{~L})$ & 4.19 & 4.7 & 4.18 & $3.68,4.62$ \\
\hline Q (L/day) & 7.50 & 10.6 & 7.47 & $4.09,10.6$ \\
\hline \multicolumn{5}{|l|}{ IIV } \\
\hline IIV on CL (\%) & 42.80 & 7.8 & 42.66 & $39.50,46.15$ \\
\hline IIV on $V_{1}(\%)$ & 27.40 & 13.1 & 27.24 & $23.34,31.37$ \\
\hline IIV on $V_{2}(\%)$ & - & - & & \\
\hline IIV on Q (\%) & - & - & & \\
\hline \multicolumn{5}{|l|}{ Residual variability } \\
\hline Proportional error (\%) & 40.20 & 2.4 & 40.20 & $38.20,42.20$ \\
\hline Additive error, $(\mu \mathrm{g} / \mathrm{ml})$ & 0.0415 & 7.6 & 0.0418 & $0.0369,0.0502$ \\
\hline \multicolumn{5}{|l|}{ Final model } \\
\hline CL (L/day) & 0.407 & 2.5 & 0.406 & $0.388,0.427$ \\
\hline $\mathrm{V}_{1}(\mathrm{~L})$ & 3.29 & 2.1 & 3.28 & $3.02,3.58$ \\
\hline $\mathrm{V}_{2}(\mathrm{~L})$ & 4.13 & 3.9 & 4.12 & $3.65,4.57$ \\
\hline Q (L/day) & 7.14 & 6.8 & 7.11 & $3.67,10.10$ \\
\hline$\Theta_{A L B C L}$ (Scaling factor of Albumin on CL) & -1.54 & 12.6 & -1.56 & $-1.94,-1.17$ \\
\hline$\Theta_{\text {ATICL }}$ (Factor of ATI on CL) & 0.471 & 22.5 & 0.480 & $0.28,0.831$ \\
\hline$\Theta_{S E X C L}($ Factor of Sex on CL) & -0.236 & 11.9 & -0.236 & $-0.291,-0.181$ \\
\hline$\Theta_{\text {WGTVI }}$ (Scaling factor of body weight on $\mathrm{V}_{1}$ ) & 0.538 & 13.5 & 0.544 & $0.394,0.700$ \\
\hline$\Theta_{S E X V I}\left(\right.$ Factor of sex on $\left.\mathrm{V}_{1}\right)$ & -0.137 & 23.2 & -0.136 & $-0.197,-0.072$ \\
\hline \multicolumn{5}{|l|}{ IIV } \\
\hline IIV for CL $(\%)$ & 37.68 & 8.5 & 37.55 & $34.50,40.99$ \\
\hline IIV for $\mathrm{V}_{1}(\%)$ & 22.11 & 16.6 & 21.84 & $17.97,25.85$ \\
\hline IIV for $\mathrm{V}_{2}(\%)$ & - & - & & \\
\hline IIV for Q (\%) & - & - & & \\
\hline \multicolumn{5}{|l|}{ Residual variability } \\
\hline Proportional error $(\%)$ & 40.30 & 2.6 & 40.30 & $38.30,42.20$ \\
\hline Additive error $(\mu \mathrm{g} / \mathrm{ml})$ & 0.0413 & 3.5 & 0.0415 & $0.0368,0.0497$ \\
\hline
\end{tabular}

\section{Full model}

Considering the information from the univariate models and specified $\triangle \mathrm{OFV}$ criterion (i.e., $\geq 3.84$ at $p \leq 0.05$, one degree of freedom), the most significant covariates to $\mathrm{CL}$ were CRP levels, antibodies to infliximab (ATI) status, albumin levels, and sex; to $\mathrm{V}_{1}$ were body weight and sex; and to $\mathrm{V}_{2}$ was body weight (Table 4). A full model was constructed with these covariates using the forward addition and backward deletion approach. This resulted in a final model that consisted of a two-compartment model with first-order elimination, with ATI status, baseline albumin, and sex influencing CL; and body weight and sex influencing $\mathrm{V}_{1}$. All parameters in the final model including the coefficients or scaling factor for the covariate effects and the random effects were all estimated with fairly good precision. Inclusion of covariates explained some of the random IIV of the population parameters in the final model for $\mathrm{CL}$ and $\mathrm{V}_{1}$. The equations for the final model are as follows:

$$
\begin{aligned}
& C L=0.407 *\left(\frac{A L B}{4.1}\right)^{-1.54} *(1.471)^{A T I} *(0.764)^{S E X} \\
& V_{1}=3.29 *\left(\frac{W G T}{77}\right)^{0.538} *(0.863)^{S E X} \\
& Q=7.14 \\
& V_{2}=4.13
\end{aligned}
$$

where ATI status $=1$ for patients who tested positive and 0 for patients who had non-positive results, and $\operatorname{sex}=1$ for females and 0 for males. 

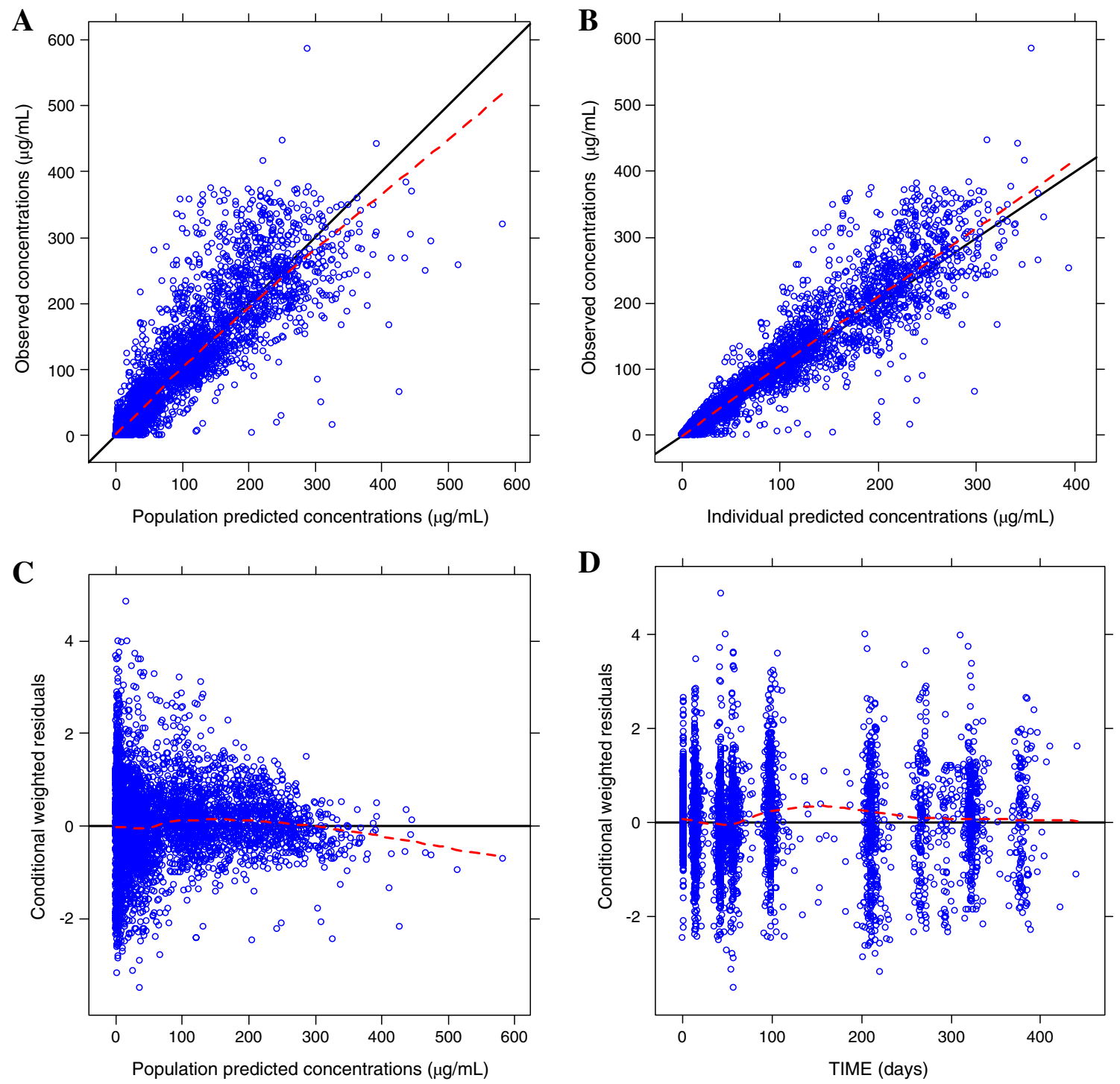

Fig. 1 Goodness-of-fit plots for the base model. Dashed lines represent the locally weighted smoothing (LOESS) of the data

Table 3 presents a summary of the parameter estimates (with associated NONMEM SE) for the final model. The 95\% CI obtained by the bootstrap technique are also included. Figure 2 presents the goodness-of-fit plots for the final model. There was very little systematic bias in CWRES where values were centered at approximately 0 with a \pm SD of \pm 0.96 , thus approximating a normal distribution.

Relationship of covariates and model parameters

\section{Effect of body weight}

Body weight was the most significant covariate on $\mathrm{V}_{1}$. Median body weight in this population was $77 \mathrm{~kg}$ (range 40-177 kg). Figures $3 \mathrm{a}$ and $\mathrm{b}$ show scatter plots of the EBEs of $\mathrm{V}_{1}$ and $\mathrm{CL}$ versus body weight, respectively.
Scatter plots comparing the random effect of $\mathrm{V}_{1}$ (ETA2) and body weight in the base model (Fig. 3c) and final model (Fig. 3d) are also illustrated. The variability due to body weight was corrected for in the final model, as shown by reduced ETA2 values and loss of the observed base model trend. The effect of body weight on CL was not statistically significant (Table 4).

\section{Effect of albumin}

Lower albumin levels appear to predict higher infliximab clearance (Fig. 4a). The relationship between random effect of CL (ETA1) and serum albumin concentrations in the base model and final model are shown in Fig. $4 \mathrm{~b}$ and c, respectively, where corrections are evident in the final model for the variability due to baseline albumin concentration. 
Table 4 Univariate analyses of selected covariates

\begin{tabular}{llll}
\hline Covariate tested & OFV & $\Delta$ OFV & $P$ value \\
\hline Base model & 27027.7 & NA & NA \\
Weight on CL & 27026.1 & -1.6 & 0.206 \\
WBC on CL & 27022.2 & -5.5 & 0.019 \\
Sex on CL & 27020.8 & -6.9 & 0.009 \\
Mayo score on CL & 27017.6 & -10.1 & 0.001 \\
Age on CL & 27017.3 & -10.4 & 0.001 \\
Weight on $V_{2}$ & 27014.5 & -13.2 & $<0.001$ \\
CRP on CL & 27010.7 & -17 & $<0.001$ \\
ATI on CL & 27001.4 & -26.3 & $<0.001$ \\
Sex on V & 26992.0 & -35.7 & $<0.001$ \\
Albumin on CL & 26968.4 & -59.3 & $<0.001$ \\
Weight on $V_{1}$ & 26950.2 & -77.5 & $<0.001$ \\
\hline
\end{tabular}

$O F V$ objective function value, $\triangle O F V$ change in objective function value, $C L$ clearance, $W B C$ white blood cell count, $V_{I}$ volume of distribution for the central compartment, $V_{2}$ volume of distribution for the peripheral compartment, $C R P \mathrm{C}$-reactive protein, $A T I$ antibodies to infliximab.

\section{Effect of antibodies to infliximab}

Thirty-three patients in ACT 1 and 2 were positive for antibodies to infliximab through week 42 and week 54 , respectively, and were included in the population PK model. These results show that mean CL was $47.1 \%$ higher for patients positive for antibodies to infliximab compared with those who were nonpositive. Figure 5a shows a box plot of CL versus antibody to infliximab status in the base model. Figure 5b (base model) and c (final model) compares the relationship of ETA1 versus antibody to infliximab status; the final model significantly corrected the base model trend.

\section{Effect of sex}

Sex was evaluated as a potential covariate on both CL and $\mathrm{V}_{1}$ (Fig. 6a and b, respectively). Results of covariate modeling showed that $\mathrm{CL}$ was about $33 \%$ lower in women, and $\mathrm{V}_{1}$ was $16 \%$ lower than in men.

Figures 6c (base model) and d (final model) compare ETA1 and sex and show that the final model significantly corrected the base model trend. Figures 6e (base model) and $\mathrm{f}$ (final model) compare ETA2 and sex, and show that the final model corrected some of the base model $\mathrm{V}_{1}$ variability.

\section{Effect of concomitant medications}

Concomitant immunomodulators azathioprine and 6-MP did not significantly impact infliximab PK. This is an important observation because concomitant immunomodulators has been shown to affect the PK of infliximab in other therapeutic indication such as RA. Corticosteroid use at baseline had only slight effects on $\mathrm{CL}$ and $\mathrm{V}_{1}$, which were not strong enough to warrant their inclusion in the model.

Influence analyses, sensitivity analyses, and model stability

Examination of the EBEs showed that two patients had suspiciously high CL values compared with the majority of patients. Further investigation showed that factors associated with high CL (in the final model) were present in these patients (i.e., development of antibodies to infliximab or low baseline albumin concentrations). Sensitivity analyses confirmed the robustness of the base and final models. The base model was rerun after excluding LLOQ values to assess the effect of the imputation method used to handle these values in the modeling process and again eliminating outliers (data excluded because of high weighted residuals $>5$ ). Parameter estimates obtained following the modified analysis did not differ significantly from those of the original analysis, although, as expected, estimates of variability were greater when the outliers were retained and covariate modeling became unstable leading to nonconvergence at the covariate modeling stage. Because prior analyses showed that the CL of infliximab varied significantly between patients who tested positive for ATI and those who did not, a sensitivity analysis was performed to determine whether there were differences in IIV by allowing the IIV on clearance to vary between the two subpopulations. The results showed that the IIV for clearance in patients who were positive for ATI was $40.7 \%$ and that for those who did not test positive for ATI was $41.2 \%$. Thus, the IIV for infliximab clearance remained similar between these two subgroups and compare very well with that of the combined population $(42.8 \%)$. Therefore, a combined analysis was deemed satisfactory.

The statistical distributions of the parameter estimates obtained from the bootstrap analyses were symmetrical around the mean and appeared to follow a normal distribution. Median values of the parameters estimated from the bootstrap analyses were in good agreement with the NONMEM point estimates, and the $95 \%$ CIs were narrow, indicating acceptable precision (Table 3). The significance of the included covariates was further supported by the bootstrap analyses, as none of the $95 \%$ CIs for the covariate effects included zero. The condition numbers of the base and final models were 22.2 and 32.5 , respectively, indicative of each model's stability. Finally, an overlay of individual Bayesian estimated PK parameter predicted curve on the raw data as a visual predictive check for representative subjects in the study (Fig. 7) shows that the models adequately fit the observed data. 

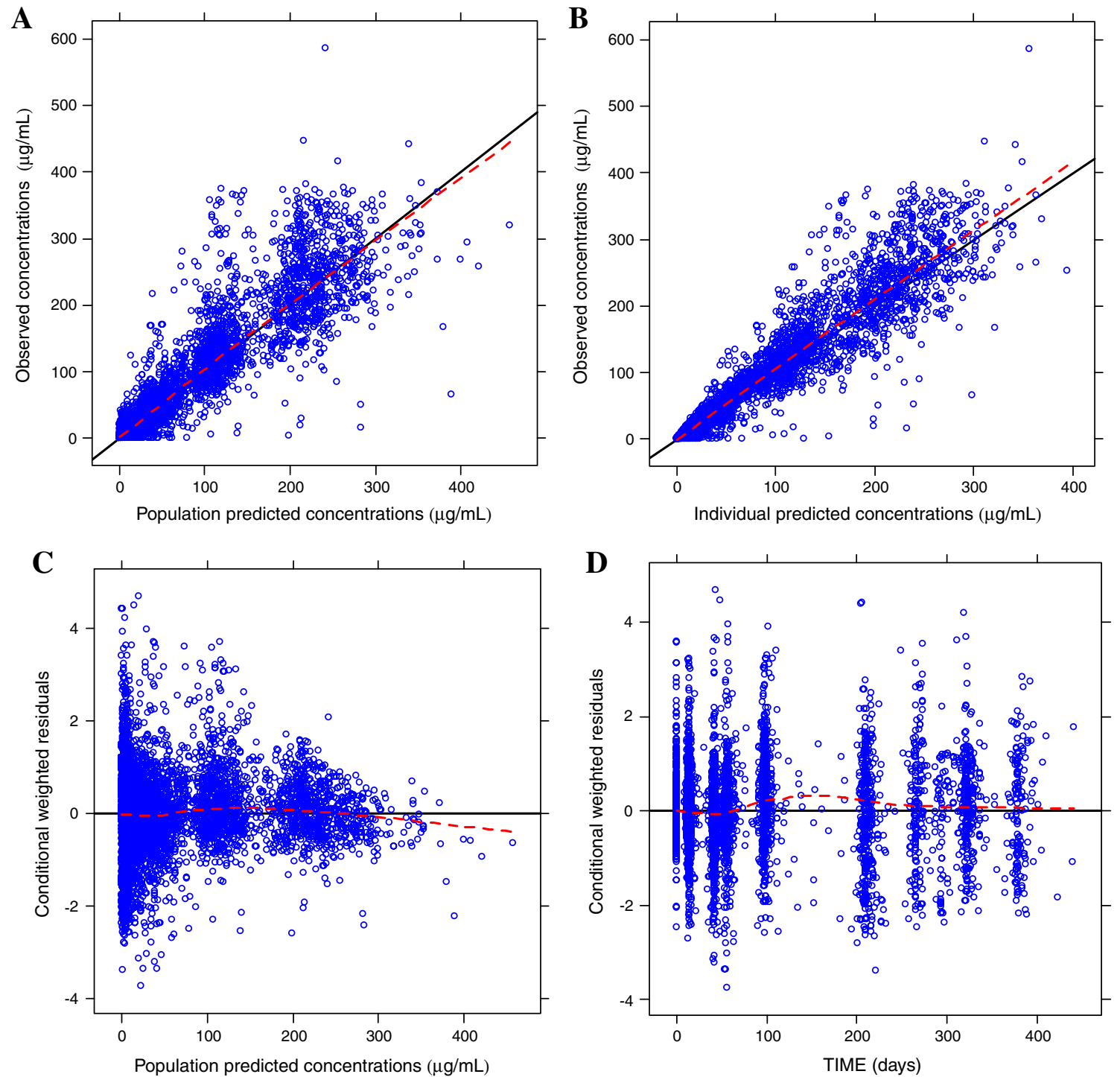

Fig. 2 Goodness-of-fit plots for the final model. Dashed lines represent the locally weighted smoothing (LOESS) of the data

\section{Discussion}

The availability of two randomized clinical trials in the same patient population allowed a thoroughly developed population PK analysis of infliximab in patients with UC. A two-compartment PK model provided reliable PK parameter and covariate effect estimation for infliximab.

$\mathrm{V}_{1}$ was estimated to be $3.29 \mathrm{~L}$ for a $77-\mathrm{kg}$ (the median body weight for this data set) individual. This is similar to that obtained in the ankylosing spondylitis patient population [9]. Infliximab steady-state volume of distribution (Vss) estimated to be $7.71 \mathrm{~L}$ for a $77-\mathrm{kg}$ patient is slightly higher than the volume of the vascular system $(5 \mathrm{~L}$ in a 70 $\mathrm{kg}$ individual). This suggests that infliximab is primarily distributed into the vascular system. These findings are consistent with the known distribution of endogenous $\operatorname{IgG}$ and some other monoclonal antibody therapies [22, 23]. In previous PK analyses of infliximab in adults administered single intravenous infusions of $3-20 \mathrm{mg} / \mathrm{kg}$, a linear relationship between the dose administered and the maximum serum concentration was observed. The reported Vss indicated that infliximab was distributed primarily within the vascular compartment [24], similar to the finding in this population PK analysis.

In our population PK analysis, the median half-life computed from the post hoc population PK parameters was approximately 14 days, with an interquartile range of 10.4 17.8 days. This value is comparable with those reported previously for infliximab [25] and for some anti-TNF- $\alpha$ monoclonal antibody therapies $[26,27]$. However, between $\mathrm{UC}$ and AS populations, Q values (7.14 L/day and $1.72 \mathrm{~L} /$ day in UC and AS, respectively) differ. Also, CL (0.407 and 
A

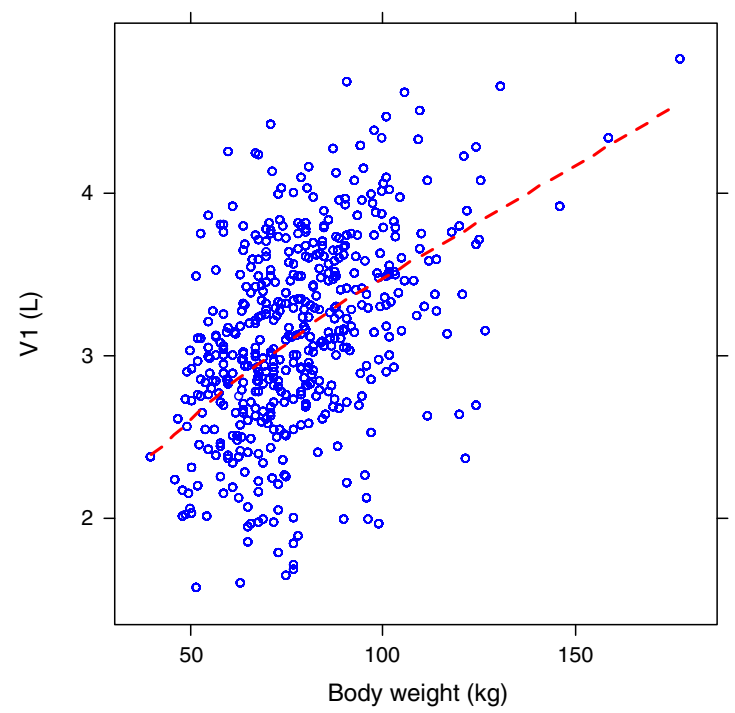

$\mathbf{C}$

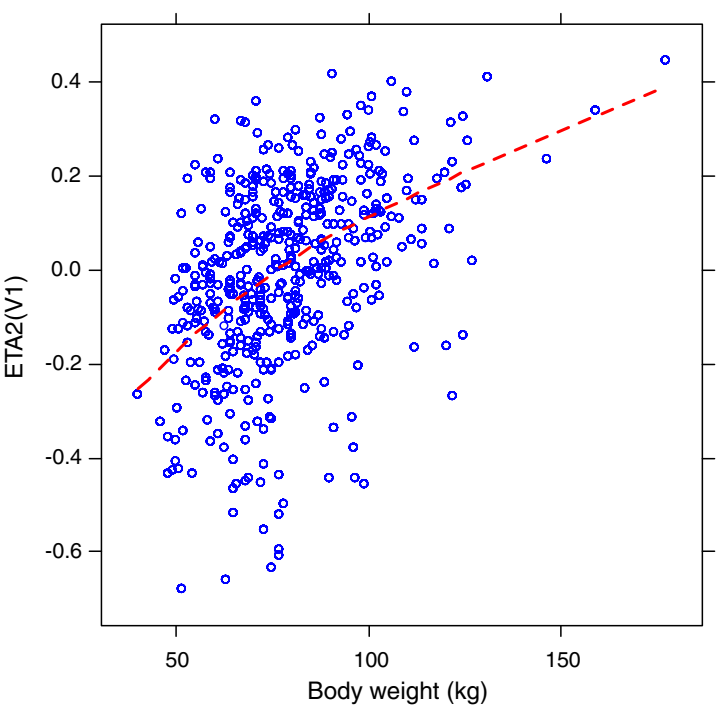

B

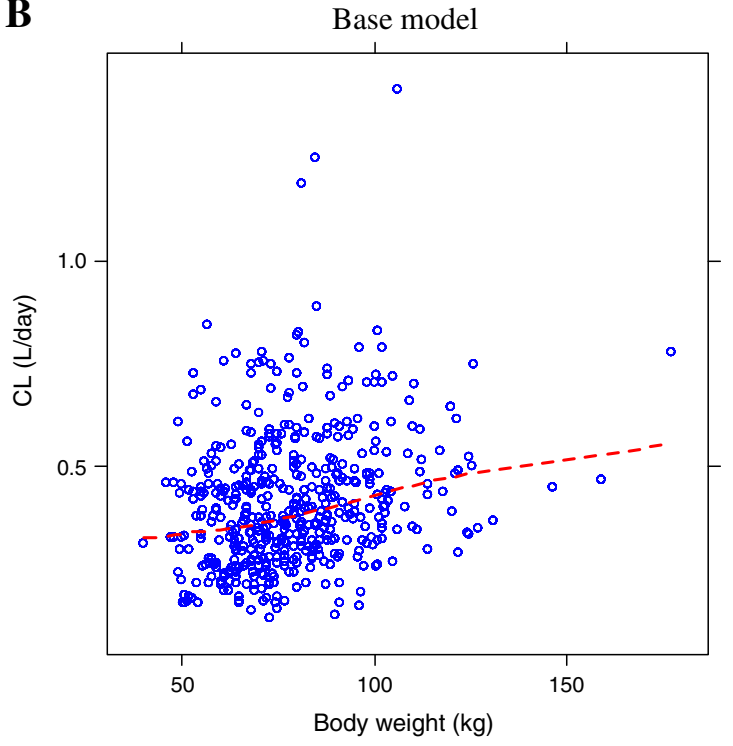

D

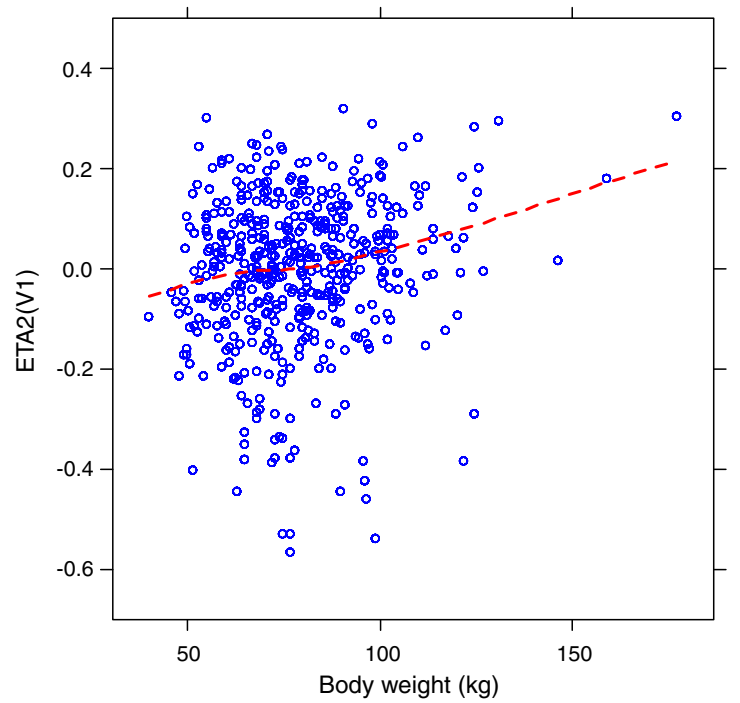

Fig. 3 Empirical Bayesian Estimates (EBEs) of $\mathrm{V}_{1}$ (panel A), clearance (CL) (panel B), and ETA2( $\mathrm{V}_{1}$ ) (panels C and D) versus body weight. $V_{l}$ volume of distribution in the central compartment, $C L$ clearance, ETA2 $\left(V_{l}\right)$ random effect of $\mathrm{V}_{1}$

0.273) appears to be different between the two populations [9]. Furthermore, the relative standard errors for Q reported by $\mathrm{Xu}$ and colleagues was higher than that obtained in the current analyses ( $27.9 \%$ vs $6.8 \%)$. In both analyses, the $\mathrm{Q}$ term is the least precisely estimated PK parameter. As discussed previously [9], generally, accurate assessment of intercompartmental clearance was difficult due to the limited sampling scheme in these late-phase clinical trials (in many instances, only preinfusion and postinfusion blood sample per dose were drawn, and on several occasions, only a postinfusion blood sample was drawn). This did not permit full characterization of the distribution phase.

The final population PK model contained four covariates: body weight, albumin, immune response status, and sex. It is apparent from the final model that body size is an important determinant of infliximab exposure. Body weight influences $\mathrm{V}_{1}$ (with a power factor of 0.54 ) but not CL. A limitation in this analysis to exploring a variety of body size parameters was the absence of patient height data. This prevented a precise computation of body-size parameters such as body mass index, lean body weight, or body surface area. However, these body-size parameters are usually highly correlated with body weight. Thus, it was reasonable to limit the interpretation of the current analyses to body weight. Similar to our observation, previous analyses also showed that body surface area or body weight are covariates of $\mathrm{V}_{1}$, although the coefficients varied for these patient populations $[4,9]$. The increase in infliximab $V_{1}$ as 
A

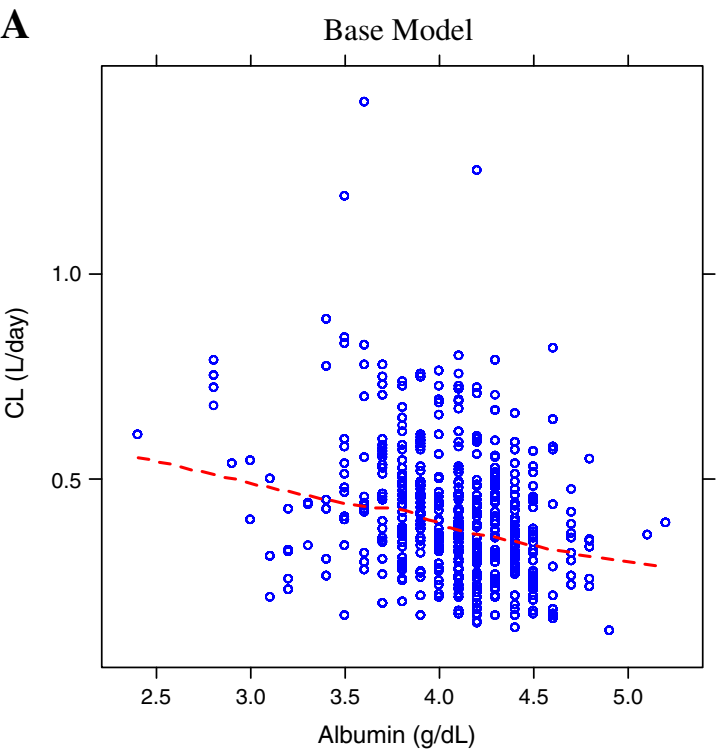

C

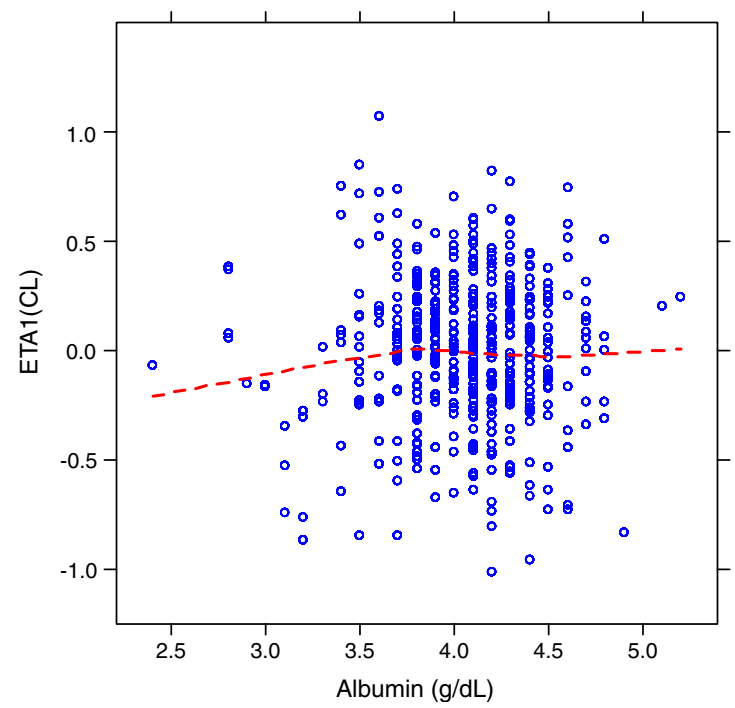

B

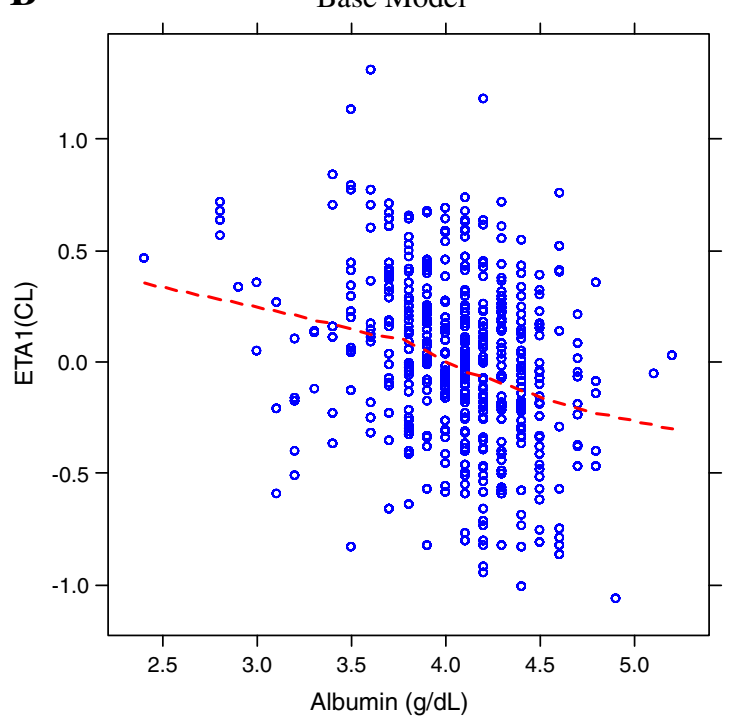

Fig. 4 Empirical Bayesian estimates (EBEs) of CL (panel A), ETA1(CL) (panels B and C) versus baseline albumin. CL learance, ETA1(CL) random effect of clearance

patient body weight increases is expected because larger body weight is associated with larger blood volume. Thus, a body weight-adjusted dosing (as is approved for infliximab) is necessary to allow equivalent exposure among all patients to mitigate a possible weight-related influence of infliximab exposure.

Development of antibodies to infliximab is a factor known to increase infliximab clearance [9]. The interaction of antibodies to infliximab with circulating infliximab may form complexes that clear more rapidly than infliximab alone. Increased $\mathrm{CL}$ in the presence of antibodies to infliximab is reconfirmed in this analysis, where an increased CL of approximately $47 \%$ was estimated for patients who developed antibodies to infliximab.
In earlier studies, patients' sex has been identified as a potential covariate influencing the PK of some other monoclonal antibodies [4, 28, 29]. In this study, patients' sex was associated with both infliximab $C L$ and $V_{1}$. As the effect of sex on CL and $V_{1}$ was directionally consistent (i.e., male patients on average had higher $\mathrm{CL}$ and $\mathrm{V}_{1}$ ), the overall effect of sex on infliximab exposure is partially negated. In addition to sex, body weight, and development of ATI - covariates that influence infliximab PK parameters in other inflammatory diseases - this analyses identifies serum albumin concentration as a novel major covariate of infliximab PK parameters in patients with UC. Patients with higher baseline serum albumin concentrations were associated with lower infliximab CL compared with those with 
A

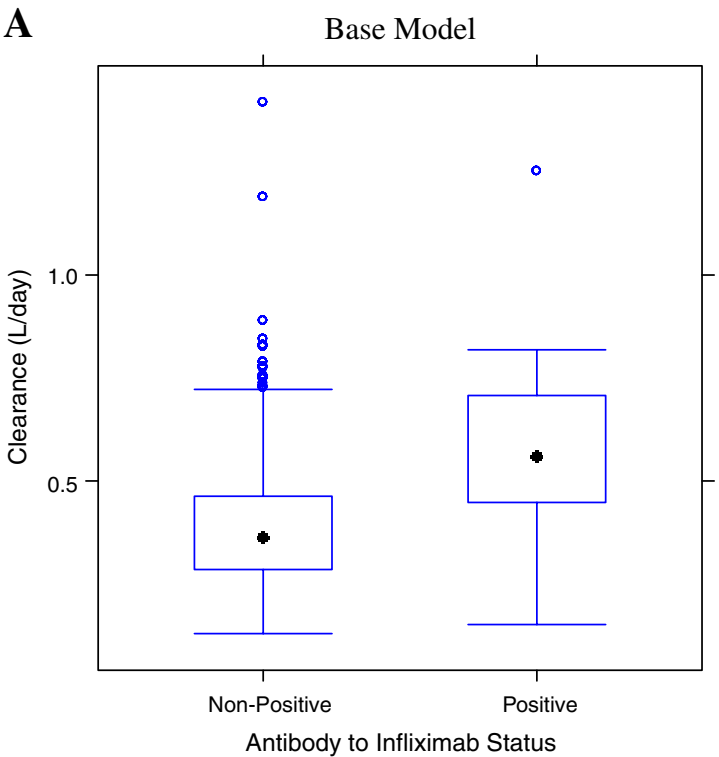

C

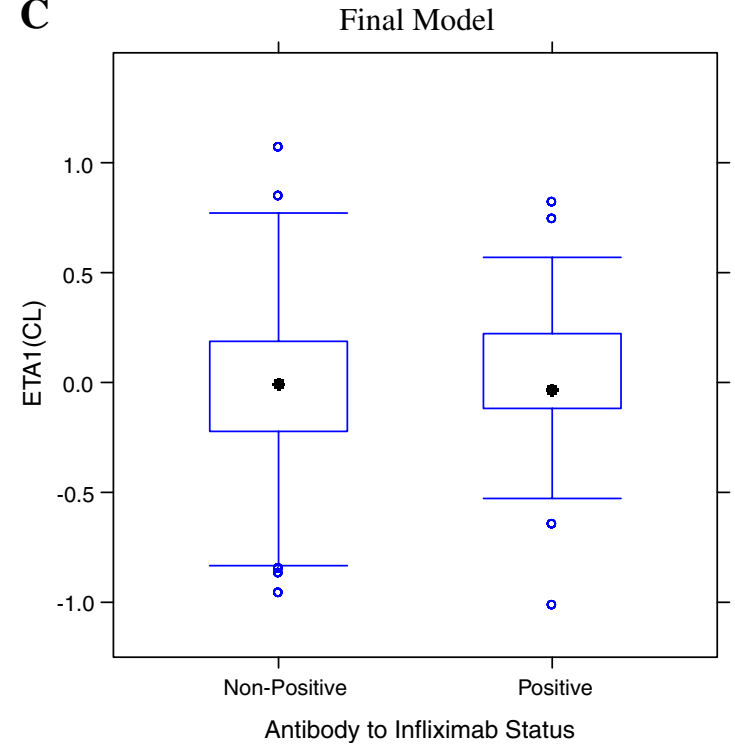

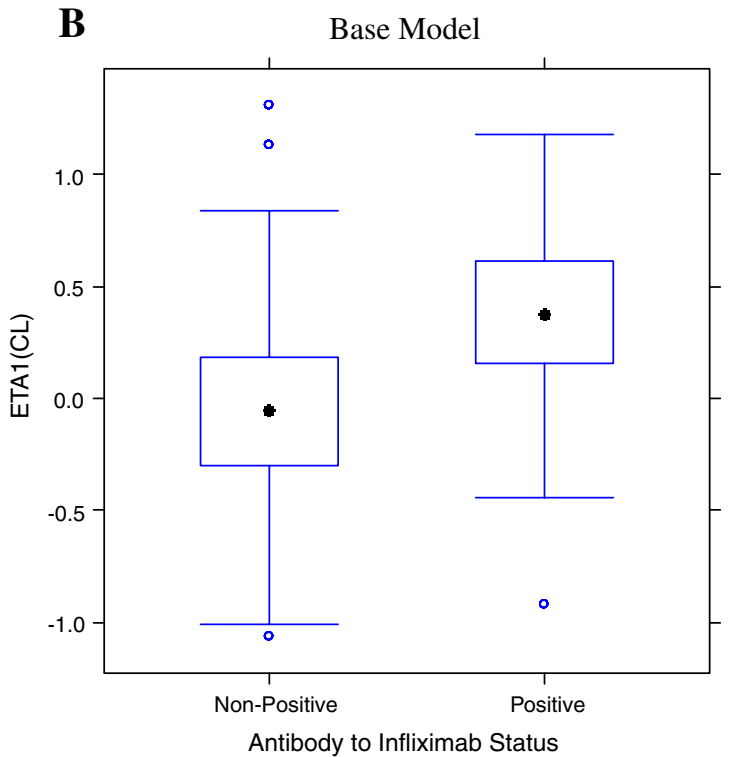

Fig. 5 Empirical Bayesian stimates (EBEs) of CL (panel A), ETA1(CL) (panels B and C) versus antibody to infliximab status. CL clearance, ETA1(CL) random effect of clearance

lower albumin concentration. Considering the interquartile range ( 3.8 and $4.3 \mathrm{mg} / \mathrm{dl})$ of baseline albumin levels in this population, and keeping all other covariates at the population mean values, the model predicts a $19.1 \%$ infliximab CL increase. Higher albumin levels were associated with lower infliximab CL and subsequently a longer infliximab half-life. To our knowledge, this is the first observation of an association between infliximab CL and serum albumin concentration. Albumin, endogenous immunoglobulins, and monoclonal antibody drugs such as infliximab are protected from catabolism by the neonatal Fc receptor (FcRn). The FcRn facilitates IgG and albumin homeostasis by recycling them across cell membranes back to the central circulatory system [30]. Thus, a higher albumin concentration could be an indicator of an increased number of FcRn and related reduced infliximab elimination. Thus, the association of serum albumin concentrations with infliximab disposition may be explained by the involvement of FcRn in the conservation of both albumin and

Fig. 6 Empirical Bayesian stimates (EBEs) of CL (panel A), $\mathrm{V}_{1}$ (panel B), ETA1(CL) for base model (panel C) and ETA1(CL) for final model (panel D); ETA2 $\left(\mathrm{V}_{1}\right)$ for base model (panel E), and ETA2 $\left(\mathrm{V}_{1}\right)$ for final model (panel F) versus Sex. $V_{I}$ volume of distribution in the central compartment, $C L$ clearance, $\operatorname{ETA2}\left(V_{1}\right)$ random effect of $\mathrm{V}_{1}$, ETA1 $(C L)$ random effect of clearance 
A

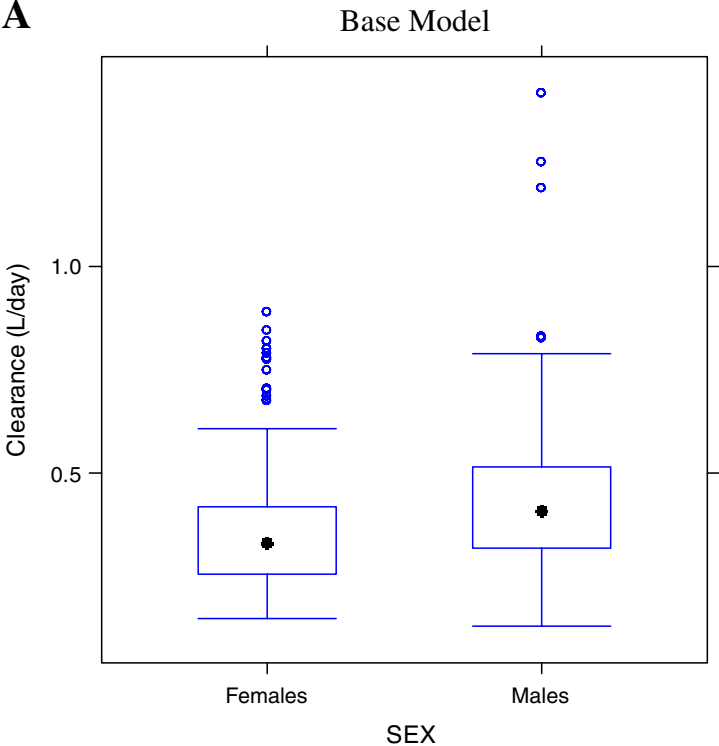

C

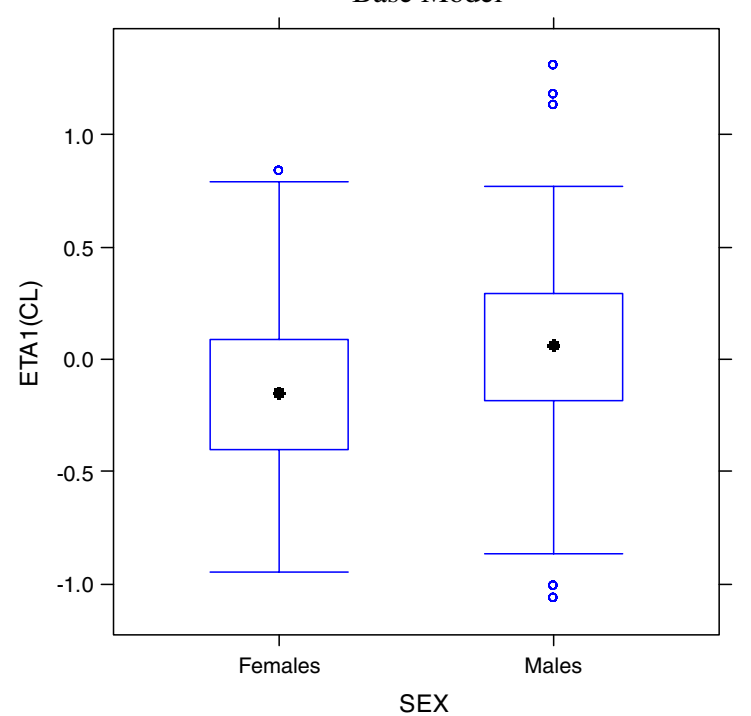

E

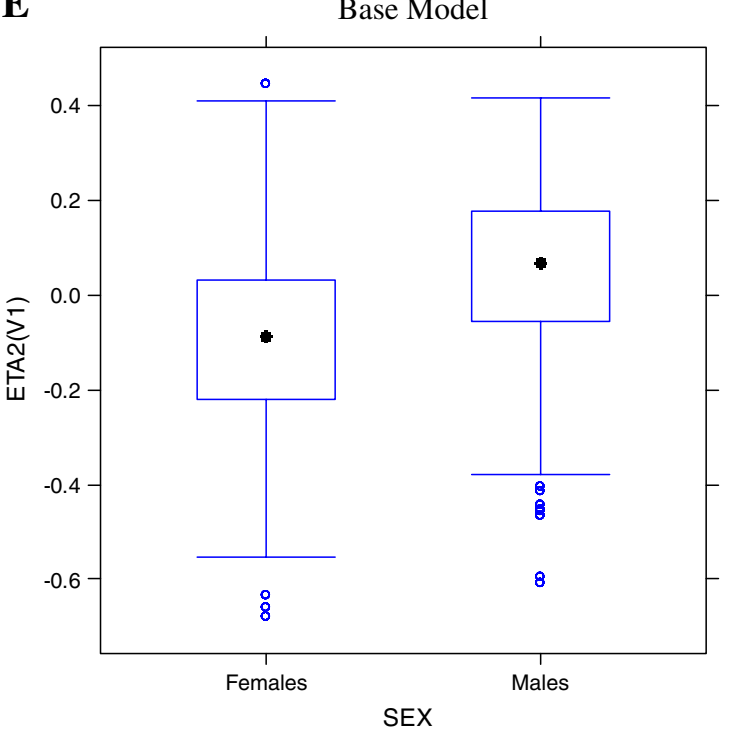

B

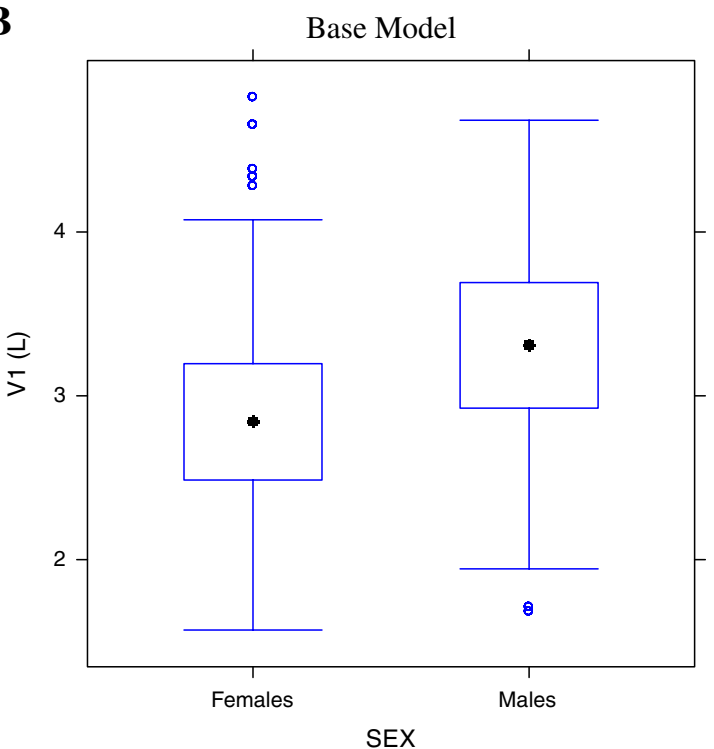

D

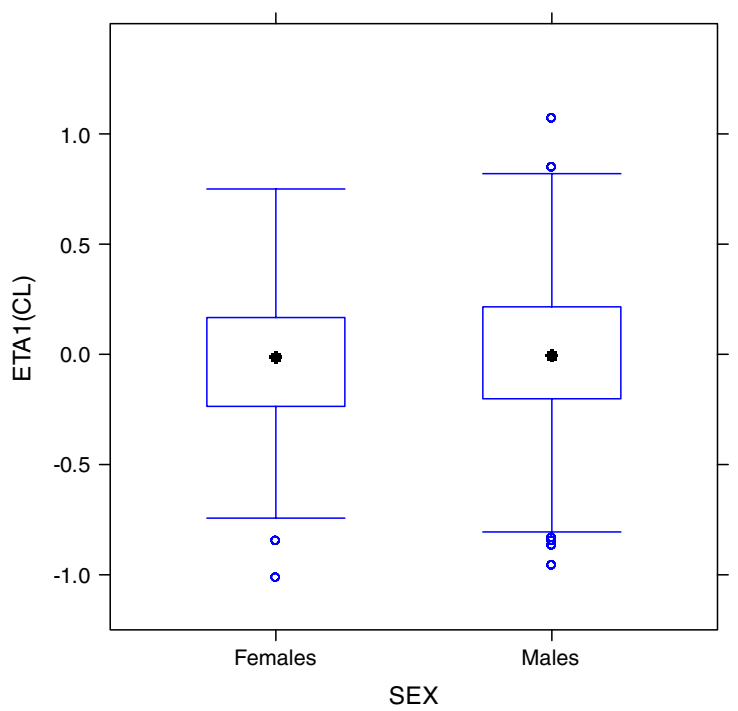

F

Final Model

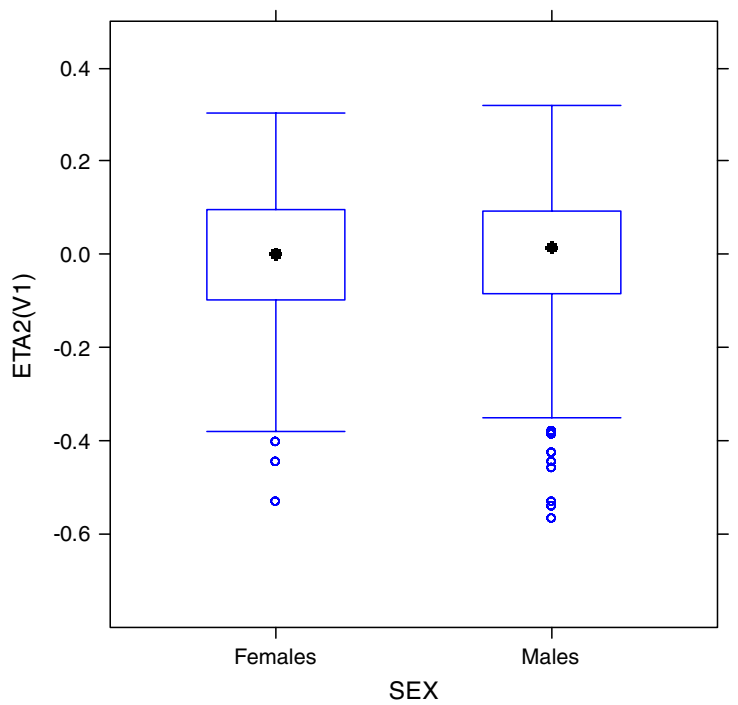


Observed and Predicted Serum Infliximab Concentration-Time Profiles for Representative Subjects
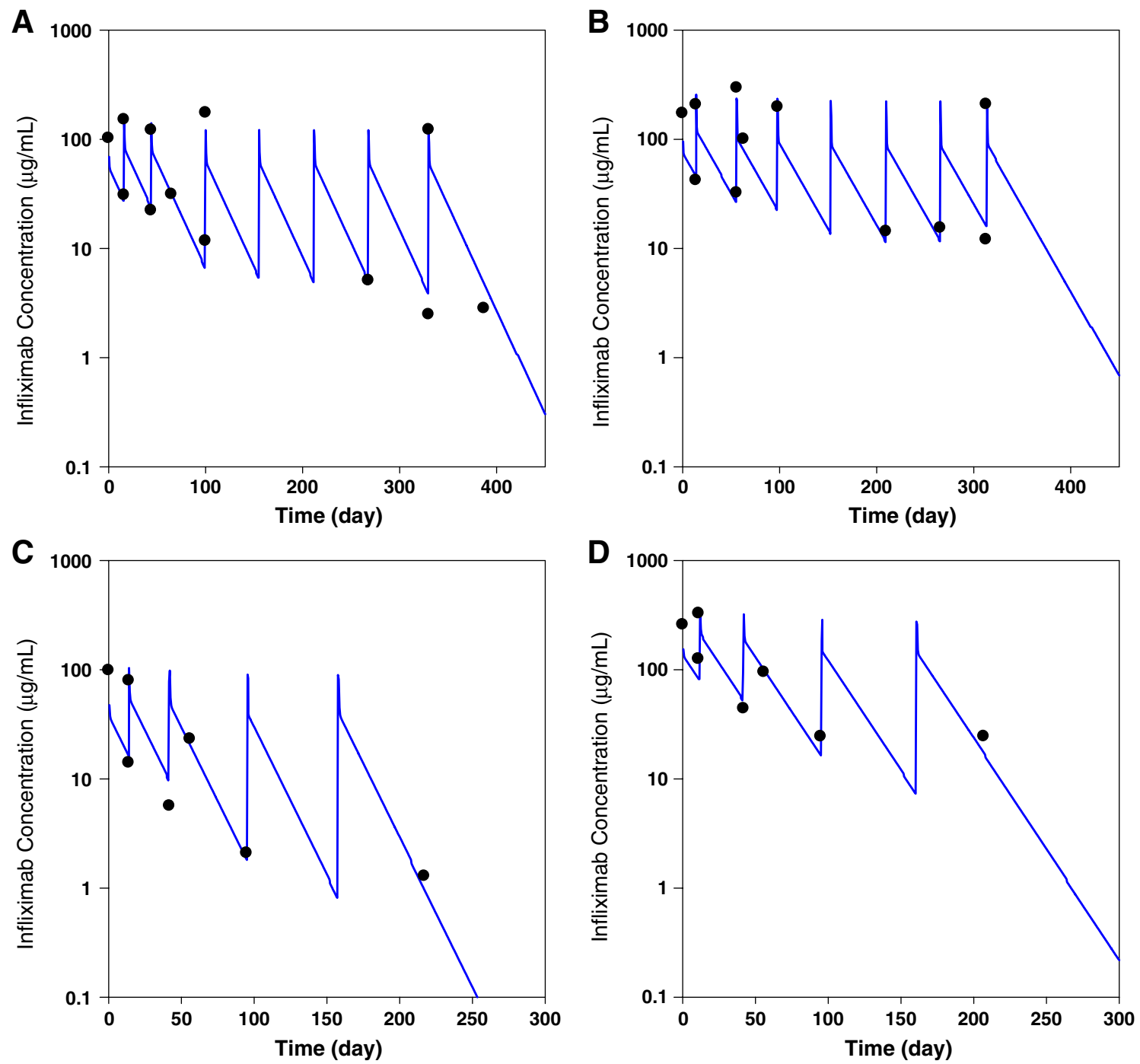

- Model Predicted Infliximab Concentration
- Observed Infliximab Concentration

Fig. 7 Visual predictive check for representative patients shown by an overlay of individual Bayesian-estimated pharmacokinetic (PK) parameter predicted curve on the raw data: representative patients in the $5 \mathrm{mg} / \mathrm{kg}$ group in the ACT 1 (panel A);representative patients in the $10 \mathrm{mg} / \mathrm{kg}$ group in ACT 1 (panel B); representative patients in the $5 \mathrm{mg} / \mathrm{kg}$ group in the ACT 2 (panel C); representative patients in the
$10 \mathrm{mg} / \mathrm{kg}$ group in the ACT 2 (panel D). Note that the dosing frequency at the beginning and early part of the study $(0,2,6$ weeks $)$ is higher than in the later period in the study when dosing was every 8 weeks. This is reflected in the higher concentrations at early time points in the graphs. ACT Active Ulcerative Colitis Trials

Immunomodulators (6-MP, azathioprine) and corticosteroids commonly coadministered with infliximab in patients with UC were not significantly associated with infliximab PK parameter variability in this analysis. This differs from previous reports where coadministration of methotrexate (an immunomodulator commonly administered with infliximab) in patients with RA were shown to clearly enhance infliximab exposure [5]. The reason for this 
disparity is unknown, but our observation is similar to that in another report that showed a lack of effect of several drugs, including immunomodulators, on infliximab PK parameters in ankylosis spondylitis patients [9]. These observations demonstrate the need to determine the PK properties of infliximab in different diseases or therapeutic settings. This is especially so because infliximab is very widely used and is indicated for several disease conditions and may be handled differently by patients in those therapeutic areas. In addition, unlike other small-molecule drugs, its disposition may not be predictable by markers of liver and kidney functions (such as ALT, AST and CRCL).

A population PK model for infliximab in patients with moderately to severely active UC identified body weight, albumin, antibody-to-infliximab positivity, and sex as key covariates influencing infliximab PK. Body-weightadjusted dosing as recommended for infliximab in its label reduced possible gross variability in infliximab exposure that could arise by the potential influence of body weight on the volume of distribution of infliximab. Serum albumin concentration is identified, for the first time, as a covariate of infliximab disposition. Its amenability to routine measurement in the clinical setting may open up the possibility of its application in the future in determining the expectation of how a particular patient will respond to infliximab.

Acknowledgement The authors thank the patients, investigators and study personnel who made the ACT studies possible. They also thank Ms. Hong Yan, of Centocor R\&D Inc. for assistance in data collation and Mr. James P. Barrett of the Medical Affairs Publication Group, Medical Affairs, Centocor Ortho Biotech, Inc. for writing and editorial support. This study was funded by Centocor R \& D Inc., Malvern, PA, USA, and Schering Plough Corp., Keniworth, NJ, USA.

Open Access This article is distributed under the terms of the Creative Commons Attribution Noncommercial License which permits any noncommercial use, distribution, and reproduction in any medium, provided the original author(s) and source are credited.

\section{References}

1. Remicade (infliximab) for IV injection. Malvern, Pa: Centocor Ortho Biotech, Inc., April 2009 (package insert)

2. Maini R, St Clair EW, Breedveld F, Furst D, Kalden J, Weisman M, Smolen J, Emery P, Harriman G, Feldmann M, Lipsky P (1999) Infliximab (chimeric anti-tumour necrosis factor $\alpha$ monoclonal antibody) versus placebo in rheumatoid arthritis patients receiving concomitant methotrexate: a randomised phase III trial. Lancet 354:1932-1939

3. Gottlieb AB, Masud S, Ramamurthi R, Abdulghani A, Romano P, Chaudhari U, Dooley LT, Fasanmade A, Wagner CL (2003) Pharmacodynamic and pharmacokinetic response to anti-tumor necrosis factor- $\alpha$ monoclonal antibody (infliximab) treatment of moderate to severe psoriasis vulgaris. J Am Acad Dermatol 48:68-75
4. Ternant D, Aubourg A, Magdelaine-Beuzelin C, Degenne D, Watier H, Picon L, Paintaud G (2008) Infliximab pharmacokinetics in inflammatory bowel disease patients. Ther Drug Monit 30:523-529

5. Klotz U, Teml A, Schwab M (2007) Clinical pharmacokinetics and use of infliximab. Clin Pharmacokinet 46:645-660

6. Fasanmade A, Olson A, Bao W, Pendley C, Davis H, Mayer L (2002) Relationship between infliximab pharmacokinetics and improvement in Crohn's disease. Gastroenterology 122(4 Suppl 1): A617-A618

7. Fasanmade AA, Marsters P, Munsanje E, Graham MA, Davis HM, Van Deventer S (2003) Infliximab pharmacokinetics and improvement in fistulizing Crohn's disease. Gastroenterology 124 (4 Suppl 1):A61

8. Clair St EW, Wagner CL, Fasanmade AA, Wang B, Schaible T, Kavanaugh A, Keystone EC (2002) The relationship of serum infliximab concentrations to clinical improvement in rheumatoid arthritis. Arthritis Rheum 46:1451-1459

9. Xu Z, Seitz K, Fasanmade A, Ford J, Williamson P, Xu W, Davis HM, Zhou H (2008) Population pharmacokinetics of infliximab in patients with ankylosing spondylitis. J Clin Pharmacol 48:681695

10. Enbrel ${ }^{\circledR}$ (etanercept) package insert; Thousand Oaks, Calif: Immunex Corporation; October 2005

11. Sandborn WJ, Hanauer SB, Katz S et al (2001) Etanercept for active Crohn's disease: A randomized, double-blind, placebocontrolled trial. Gastroenterology 121:1088-1094

12. Tracey D, Klareskog L, Sasso EH, Salfeld JG, Tak PP (2008) Tumor necrosis factor antagonist mechanisms of action: A comprehensive review. Pharmacol Ther 117:244-279

13. Rutgeerts P, Sandborn WJ, Feagan BG, Reinisch W, Olson A, Johanns J, Travers S, Rachmilewitz D, Hanauer SB, Lichtenstein GR, de Villiers WJ, Present D, Sands BE, Colombel JF (2005) Infliximab for induction and maintenance therapy for ulcerative colitis. N Engl J Med 353:2462-2476

14. Schroeder KW, Tremaine WJ, Ilstrup DM (1987) Coated oral 5aminosalicylic acid therapy for mildly to moderately active ulcerative colitis: a randomized study. N Engl J Med. 317:1625-1629

15. Hanauer SB, Wagner CL, Bala M, Mayer L, Travers S, Diamond RH, Bao W, Rutgeerts P (2004) Incidence and importance of antibody responses to infliximab after maintenance or episodic treatment in Crohn's disease. Clin Gastroenterol Hepatol 2:542-553

16. Cockroft DW, Gault MH (1976) Prediction of creatinine clearance from serum creatinine. Nephron 16:31-41

17. Holford NH (2007) Wings for NONMEM, http://wfn.sourceforge. net

18. Jonsson EN, Karlsson MO (1999) Xpose - an S-PLUS based population pharmacokinetic/pharmacodynamic model building aid for NONMEM. Comput Methods Programs Biomed 58:51-64

19. Karlsson MO, Savic RM (2007) Diagnosing model diagnostics. Clin Pharmacol Ther 82:17-20

20. Ette EI (1997) Stability and performance of a population pharmacokinetic model. J Clin Pharmacol 37:486-495

21. Brendel K, Comets E, Laffont C, Laveille C, Mentre F (2006) Metrics for external model evaluation with an application to the population pharmacokinetics of gliclazide. Pharm Res 23:20362049

22. Roskos LK, Davis CG, Schwab GM (2004) The clinical pharmacology of therapeutic monoclonal antibodies. Drug Dev Res 61:108-120

23. Kuester K, Kloft C (2007) Pharmacokinetics and monoclonal antibodies. In: Meibohm B (ed) Pharmacokinetics and pharmacodynamics of biotech drugs: principles and case studies in drug development. Wiley-VCH, Weinheim, pp 45-92

24. Siddiqui MA, Scott JL (2006) Infliximab: A review of its use in Crohn's disease and rheumatoid arthritis. Drug 66:2179-2208 
25. Schwab M, Klotz U (2001) Pharmacokinetic Considerations in the Treatment of Inflammatory Bowel Disease. Clin Pharmacokinet 40:723-751

26. Cimzia (certolizumab) [prescribing information], UCB, Inc., Smyrna, GA, April 2008

27. Humira (adalimumab) [prescribing information], Abbott Laboratories, Abbott Park, IL, December 2008

28. Ng CM, Bruno R, Combs D, Davies B (2005) Population pharmacokinetics of rituximab (Anti-CD20 Monoclonal Anti- body) in rheumatoid arthritis patients during a phase II clinical trial. J Clin Pharmacol 45:792-801

29. Nestorov I, Zitnik R, Ludden T (2004) Population pharmacokinetic modeling of subcutaneously administered etanercept in patients with psoriasis. J Pharmacokinet Pharmacodyn 31:463-490

30. Kim J, Hayton WL, Robinson JM, Anderson CL (2007) Kinetics of FcRn-mediated recycling of $\mathrm{IgG}$ and albumin in human: Pathophysiology and therapeutic implications using a simplified mechanism-based model. Clin Immunol 122:146-155 